\title{
Presynaptic Inhibition of Primary Olfactory Afferents Mediated by Different Mechanisms in Lobster and Turtle
}

\author{
Matt Wachowiak and Lawrence B. Cohen \\ Department of Cellular and Molecular Physiology, Yale University School of Medicine, New Haven, Connecticut 06520, \\ and Marine Biological Laboratory, Woods Hole, Massachusetts 02543
}

Presynaptic regulation of transmission at the first olfactory synapse was investigated by selectively imaging axon terminals of receptor neurons in the lobster olfactory lobe and turtle olfactory bulb. In both species, action potential propagation into axon terminals after olfactory nerve stimulation was measured using voltage-sensitive dyes. In addition, in the turtle, calcium influx into terminals was measured by selectively labeling receptor neurons with dextran-conjugated calcium indicator dyes. In the lobster, application of the inhibitory transmitters GABA or histamine suppressed action potentials in the terminals. The suppression was blocked by picrotoxin and cimetidine, respective antagonists to lobster GABA and histamine receptors. These results suggest that previously characterized GABA and histaminergic interneurons regulate olfactory input by suppressing action potential propagation into axon terminals of olfactory afferents. In contrast, in the turtle olfactory

Presynaptic inhibition of primary afferent fibers is an important feature of many vertebrate and invertebrate sensory systems, including cutaneous and muscle stretch receptor afferents in mammals (for review, see Rudomin, 1990; Watson, 1992) and stretch receptor, proprioreceptor, and mechanoreceptor afferents of arthropods (Blagburn and Sattelle, 1987; Burrows and Laurent, 1993; Clarac and Cattaert, 1996). Functional roles of presynaptic afferent inhibition include preventing habituation, sharpening the receptive fields of afferent fibers, and serving as a mechanism for gain control of sensory input to the CNS (Watson, 1992). In the olfactory system, studies in both invertebrates and vertebrates have suggested that presynaptic inhibition may play a role in processing olfactory input. In the cockroach, GABAergic interneurons form presynaptic contacts with olfactory receptor axon terminals (Distler and Boeckh, 1997). In the vertebrate olfactory bulb, physiological evidence for presynaptic inhibition comes from measurements of postsynaptic activity elicited by olfactory nerve shock and recorded with field potentials, intracellular mitral cell recordings, or optical imaging, all of which show that nerve shock causes a long-lasting suppression of responses to subsequent shocks that cannot be explained by inhibition of postsynaptic olfactory bulb neurons (Orbach and Cohen, 1983;

\footnotetext{
Received April 14, 1999; revised Aug. 5, 1999; accepted Aug. 5, 1999.

This work was supported by National Institutes of Health Grant NS08437 and a Marine Biological Laboratory Summer Research Fellowship. We thank Barry Ache, Charles Greer, Brian Salzberg, and Dejan Zecevic for useful comments on this manuscript.

Correspondence should be addressed to Dr. Matt Wachowiak, Department of Cellular and Molecular Physiology, Yale University School of Medicine, 333 Cedar Street, New Haven, CT 06510.

Copyright (C) 1999 Society for Neuroscience $\quad 0270-6474 / 99 / 198808-10 \$ 05.00 / 0$
}

bulb, neither GABA nor dopamine had any effect on receptor cell action potentials as measured with voltage-sensitive dyes. However, calcium influx into axon terminals was reduced by the GABA $_{B}$ agonist baclofen and the dopamine $D_{2}$ agonist quinpirole, and paired-pulse suppression of calcium influx was reduced by the $G_{A B A}$ antagonist saclofen. These results indicate that in the turtle, GABA and dopamine mediate presynaptic inhibition not by affecting action potentials directly, as in the lobster, but by reducing calcium influx via $\mathrm{GABA}_{\mathrm{B}}$ and dopamine $D_{2}$ receptors. Thus, although mediated by different cellular mechanisms, presynaptic regulation of olfactory input to the CNS, via dual synaptic pathways, is a feature common to vertebrates and invertebrates. This inhibition may be important in the processing of olfactory information.

Key words: olfactory bulb; presynaptic inhibition; imaging; voltage-sensitive dye; calcium dye; GABA; dopamine; histamine
Mori et al., 1984; Nickell et al., 1994; Potapov, 1985; Keller et al., 1998). In the latter three studies, the suppression was mimicked by the $\mathrm{GABA}_{\mathrm{B}}$ receptor agonist baclofen, suggesting that $\mathrm{GABA}_{\mathrm{B}}$ receptors may mediate presynaptic inhibition. In addition, $\mathrm{D}_{2}$ dopamine receptors are present in the olfactory nerve layer of the rat olfactory bulb (Nickell et al., 1991), leading to the hypothesis that $\mathrm{D}_{2}$ receptors may also regulate transmission at the first olfactory synapse. However, a direct physiological demonstration of the events underlying presynaptic inhibition was hampered by the inaccessibility of presynaptic terminals or their postsynaptic sites to conventional electrode-based recording techniques.

In a recent study (Wachowiak and Cohen, 1998), we used voltage-sensitive dyes to record action potentials selectively from olfactory receptor axon terminals in the spiny lobster and demonstrated that presynaptic afferent inhibition is present in this system. The present study was designed to characterize the role of inhibitory transmitters in mediating presynaptic afferent inhibition in the lobster and to test whether presynaptic inhibition also regulates olfactory input to the olfactory bulb of a vertebrate, the box turtle Terapene carolina. In the turtle, we measured action potential invasion of receptor cell axon terminals as well as calcium influx into the terminals after anterograde labeling with a dextran-conjugated calcium indicator (Friedrich and Korsching, 1997). Our findings indicate that in the lobster, GABA and histamine can each suppress action potential invasion of olfactory axon terminals, whereas in the turtle the inhibitory transmitters GABA and dopamine cause no such suppression. However, GABA and dopamine do appear to regulate calcium influx into the terminals of turtle olfactory afferents via $\mathrm{GABA}_{\mathrm{B}}$ and $\mathrm{D}_{2}$ receptor activation, respectively. 


\section{MATERIALS AND METHODS}

Preparations. Optical signals were recorded from three in vitro preparations: the olfactory lobe of the spiny lobster Panulirus argus, using a perfused, isolated brain preparation; the lobster antennular nerve, using a cut section of nerve; and the olfactory bulb of the turtle T. carolina, using a superfused hemisected bulb preparation. The lobster brain and turtle olfactory bulb preparations have been described previously (Berkowicz et al., 1994; Wachowiak and Ache, 1994).

In the lobster brain preparation, the animal was chilled on ice and decapitated, and the brain was cannulated via the medial artery and perfused with oxygenated Panulirus saline. The brain was then removed from the head, along with associated blood vessels, by cutting all nerve roots and the optic tracts leading to the protocerebrum. The brain was pinned in a Sylgard recording chamber with the olfactory lobes facing upward and was desheathed, and the left antennular nerve was placed in a glass suction electrode for stimulation.

In the nerve preparation, a 5-7 $\mathrm{mm}$ length of nerve was excised just distal to the point where the nerve entered the brain and secured in a recording chamber containing two suction electrodes. One suction electrode was used to stimulate from one cut end, and the other electrode was used to record the compound action potential from the other end. The nerve was continuously superfused with oxygenated saline as in the isolated brain preparation.

In the turtle preparation, animals were anesthetized by chilling on ice for $2-3 \mathrm{hr}$ and decapitated, and the forebrain including the intact olfactory bulbs was removed and placed in chilled turtle Ringer's solution bubbled with $95 \% \mathrm{O}_{2} / 5 \% \mathrm{CO}_{2}$. The olfactory bulb from one side was isolated by making a coronal cut through the forebrain just caudal to the bulb. The bulb was then hemisected in the horizontal plane, and one hemisection was pinned down in the recording chamber with the outer surface facing upward. The olfactory nerve, which is large and distinct in turtles, was drawn into a suction electrode for stimulation. The hemisection was kept continuously superfused with turtle Ringer's solution (1-2 $\mathrm{ml} / \mathrm{min}$ ) via the same system as for the lobster, with the perfusion cannula secured in the bath.

Drug delivery and solution replacement. A three-way solenoid valve (Cole-Parmer, Chicago, IL) allowed switching between normal and $\mathrm{Ca}^{2+}$-free saline solutions in the perfusion system. Trials with a marker dye in the solution showed that complete replacement of the solution occurred at the tip of the perfusion cannula within 2 min at a flow rate of $0.5 \mathrm{ml} / \mathrm{min}$. Replacement of saline in the tissue of the lobster brain or turtle bulb was presumably slower. In the lobster the brain was perfused with $\mathrm{Ca}^{2+}$-free solution for 5-10 min before further trials, whereas in the turtle bulb 15-20 min was allowed for solution replacement.

Transmitter agonists and antagonists were introduced into the background perfusion via a manual four-way loop injector (Rheodyne, Rohnert Park, CA). Injected solutions reached the cannula tip within 30 sec, and the size of the injection loop was large enough to allow a sustained peak concentration for up to $4 \mathrm{~min}$. Normally, trials were performed $2 \mathrm{~min}$ after drug injection. The drug concentrations reported here are those injected into the perfusion system. No attempt was made to correct for possible dilution in the brain or in the bath.

Optical recordings. For the voltage-sensitive dye experiments, lobster brain tissue was stained with di-2-ANEPHQ (JPW-2081; synthesized by J. P. Wuskell and L. M. Loew, University of Connecticut Health Center, Farmington, CT) by introducing $2 \mathrm{ml}$ dye $(0.06 \mathrm{mg} / \mathrm{ml})$ into the perfusion line or by applying dye $(0.36 \mathrm{mg} / \mathrm{ml})$ in the bath for $20 \mathrm{~min}$. Dye perfusion resulted in uniform staining of the brain, whereas bath application stained only the outermost $50-100 \mu \mathrm{m}$ of tissue. Turtle olfactory bulb tissue was stained by bath application of di-4-ANEPPS $(0.05 \mathrm{mg} / \mathrm{ml})$ or RH-414 $(0.05 \mathrm{mg} / \mathrm{ml})$ (Grinvald et al., 1994) (both from Molecular Probes, Eugene, OR) for $30 \mathrm{~min}$.

For the turtle calcium-dye experiments, olfactory receptor axon terminals were selectively labeled by anterograde transport of the dextranconjugated calcium indicator Calcium Green-1 or Calcium Crimson (both $10 \mathrm{kDa}$; Molecular Probes) applied to the olfactory epithelium using a protocol adapted from Friedrich and Korsching (1997). Turtles were first chilled on ice for 1-2 hr, then placed upside down with the mouth held open; $25-60 \mu \mathrm{l}$ of a $2 \%$ dye solution dissolved in $0.1 \mathrm{M} \mathrm{NaCl}$ plus $0.5 \%$ Triton $\mathrm{X}-100$ was injected into each naris. The pharyngeal opening of each naris was plugged to prevent leakage, and the epithelium was stained for 10-20 min, after which the plugs were removed and the mouth closed, allowing the animal to expel the dye from the nose. The turtles were then held at room temperature for 4-12 d before recording. Sections through the nares and olfactory bulb of experimental animals revealed fluorescence in the olfactory cell body layer of the epithelium and the olfactory nerve and glomerular layers of the olfactory bulb. Although glomeruli could be clearly distinguished by the labeled fibers, no fluorescence was visible in subglomerular layers (data not shown).

To record voltage-sensitive dye and Calcium Crimson signals, the preparation was illuminated with light from a tungsten halogen lamp passed through a $520 \pm 45 \mathrm{~nm}$ interference filter, reflected from a $590 \mathrm{~nm}$ long-pass dichroic mirror, and focused on the preparation using a $25 \mathrm{~mm}$, $0.95 \mathrm{f}$, video lens (Kleinfeld and Delaney, 1996). For Calcium Green signals, a $460 \pm 30 \mathrm{~nm}$ interference filter and a $515 \mathrm{~nm}$ dichroic mirror were used. In all experiments, a 3.5-mm-diameter field was imaged with a 0.4 NA onto an array of 464 photodiodes. Each photodiode received light from a square region of the object plane $\sim 150 \mu \mathrm{m}$ on a side. The photocurrents from each diode were amplified separately, bandpassfiltered by the amplifiers $(0.07-500 \mathrm{~Hz})$, and digitized at $1 \mathrm{kHz}$ under the control of NeuroPlex software (OptImaging, LLC, Fairfield, CT) on an IBM-PC computer. Additional digital filtering and spatial averaging were performed off-line using NeuroPlex. All recordings were from single trials. The mean photocurrent from the diodes was $\sim 8 \mathrm{nA}$ for the voltage-sensitive dye recordings (average from five representative preparations) and $0.4 \mathrm{nA}$ for the calcium dye recordings. Because we were interested in measuring population responses from a large fraction of the neurons in a particular region (e.g., olfactory nerve, olfactory lobe, olfactory bulb), spatial averages of signals from four to nine adjacent photodiodes were used in measuring all responses. The photodiodes were chosen such that they covered $10-50 \%$ of the region of interest. However, measurements made with single photodiodes consistently showed the same effects as reported from the spatial averages. To determine the detector locations relative to the image of the preparation, a high-resolution image of the acquisition area was obtained by deflecting the light path to a $768 \times 494$ pixel CCD camera (Dage MTI, Michigan City, IN).

Experimental protocol and data analysis. The experimental protocol was to record responses to a pair of electrical shocks to the olfactory nerve [300-400 msec interstimulus interval (ISI)] with the lobster brain or turtle bulb in a series of different solutions (for example, normal saline, $\mathrm{Ca}^{2+}$-free saline, $\mathrm{Ca}^{2+}$-free saline with agonist or antagonist, recovery in $\mathrm{Ca}^{2+}$-free, and recovery normal salines). A single series of solution changes could take up to $40 \mathrm{~min}$. For the voltage-sensitive dye experiments, the overall signal amplitude often decreased during this time, probably attributable to dye washout (we did not detect a significant amount of photobleaching), especially in the lobster preparations because of the relatively low hydrophobicity of JPW-2081P. To correct for this effect, the rate of washout was assumed to be linear and was calculated based on the amplitudes of test responses in normal saline at the beginning and end of each experiment. Amplitude measurements were then standardized using this time-dependent correction factor. The time-corrected data were used to generate the numbers reported in the text and shown in the summary figures. Because these corrections were not large, uncorrected data are shown in the traces of Figures 1, 2, 4, 6, 7 , and 8 . No correction was used for the calcium dye experiments because we saw no sign of dye washout or photobleaching. In all traces in the figures, fluorescence changes corresponding to a depolarization and an increase in $\mathrm{Ca}^{2+}$ are plotted upward, regardless of the direction of change in fluorescence.

Solutions. Normal Panulirus saline consisted of (in mM): $460 \mathrm{NaCl}, 13$ $\mathrm{KCl}, 13 \mathrm{CaCl}_{2}, 10 \mathrm{MgCl}_{2}, 14 \mathrm{Na}_{2} \mathrm{SO}_{4}, 1.7$ glucose, 3 HEPES, pH 7.4. Normal turtle Ringer's solution consisted of (in $\mathrm{mM}$ ): $96.5 \mathrm{NaCl}, 2.6 \mathrm{KCl}$, $4 \mathrm{CaCl}_{2}, 2 \mathrm{MgCl}_{2}, 10$ glucose, $31.5 \mathrm{NaHCO}_{3}, \mathrm{pH}$ 7.4. For $\mathrm{Ca}^{2+}$-free, high- $\mathrm{Mg}^{2+}$ solutions (lobster and turtle salines), the $\mathrm{CaCl}_{2}$ was replaced with $\mathrm{MgCl}_{2}$. In addition, $1 \mathrm{~mm}$ EGTA was added to the $\mathrm{Ca}^{2+}$-free turtle Ringer's solution. GABA, histamine, quinpirole, (-)-baclofen, (-)saclofen, DL-2-amino-5-phosphonovaleric acid (AP5), and 6,7dinitroquinoxaline-2,3-dione (DNQX) were prepared from frozen aliquots of stock solution (1-100 mM). Dopamine was prepared fresh daily in turtle Ringer's solution plus $0.1 \%$ sodium metabisulfate to prevent oxidation. Picrotoxin, cimetidine, and bicuculline methiodide were prepared fresh daily. All solutions were at $\mathrm{pH}$ 7.4. Agonist and antagonists were obtained from RBI (Natick, MA), and all other chemicals were obtained from Sigma (St. Louis, MO) or Fisher (Fair Lawn, NJ).

Animals. Spiny lobsters, obtained in the Florida Keys by the Keys Marine Laboratory, were kept in flow-through seawater $\left(20-22^{\circ} \mathrm{C}\right)$ at the Marine Biological Laboratory (Woods Hole, MA). Turtles were obtained from Charles D. Sullivan Co. (Nashville TN) and kept at $14^{\circ} \mathrm{C}$ until ready for use. All experiments were performed at room temperature $\left(22-24^{\circ} \mathrm{C}\right)$. Experimental protocols were approved by the Yale 


\section{LOBSTER - VOLTAGE DYE}

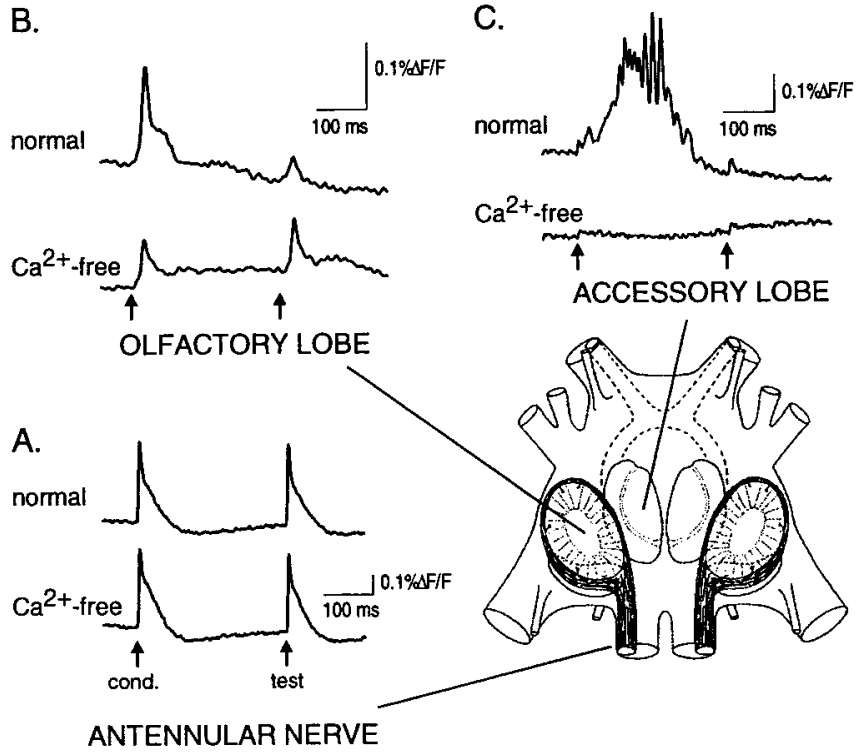

Figure 1. Voltage-sensitive dye signals evoked by paired-pulse stimulation in normal (top traces) and zero $\mathrm{Ca}^{2+} /$ high- $\mathrm{Mg}^{2+}$ saline (bottom traces), recorded from three different locations in the isolated lobster brain. Paired-pulse suppression is not seen in the olfactory nerve $(A)$ but is dramatic in the olfactory and accessory lobes $(B, C)$. A schematic diagram of the brain, bottom right, shows the lateral olfactory lobes, innervated by primary olfactory afferents in the antennular nerves, and the medial accessory lobes, which receive no primary afferent input. Arrows indicate the conditioning and test stimuli ( $2 \mathrm{msec}$ duration). Each trace is the spatial average of five to seven photodetectors. In addition to analog filtering before data acquisition $(0.07-500 \mathrm{~Hz})$, the traces were digitally filtered using a low-pass Gaussian filter and a high-pass RC filter $(A, 2.8-100 \mathrm{~Hz} ; B, 1.4-40 \mathrm{~Hz} ; C, 1.4-100 \mathrm{~Hz})$. The undershoot after the large spiking responses (both traces in $A$, top traces in $B$ and $C$ ) is an artifact of the digital high-pass RC filter. See Results for description of evoked responses.

Animal Care and Use Committee and by the Marine Biological Laboratory Institutional Animal Care and Use Committee.

\section{RESULTS}

\section{Evoked optical responses in lobster olfactory lobe}

Optical signals arising selectively from lobster olfactory receptor cell axon terminals were isolated by delivering paired electrical shocks to the olfactory (antennular) nerve and by perfusing the brain with $\mathrm{Ca}^{2+}$-free/high- $\mathrm{Mg}^{2+}$ saline. Figure 1 shows responses evoked by paired-pulse nerve stimulation as recorded from three sites in a preparation stained by perfusion of voltagesensitive dye: the antennular nerve $(A)$, the olfactory lobe $(B)$, and a second-order olfactory neuropile, the accessory lobe $(C)$. In normal saline (Fig. 1, top traces) the typical response patterns were as follows. In the antennular nerve, we observed shortlatency spikes reflecting directly evoked action potentials in response to both the conditioning and test pulses. In contrast, the olfactory lobe signal evoked by a conditioning pulse consisted of a large, rapid transient followed by a smaller component consisting of a slow depolarization and, occasionally, a series of two to four small-amplitude spikes (not apparent in Fig. 1). This complex response presumably reflects primary afferent as well as postsynaptic activity. The test pulse evoked only a simple smallamplitude spike with no late component. Finally, in the accessory lobe, the conditioning pulse evoked a short-latency, very small- amplitude depolarization followed by a complex long-latency response, also consisting of a depolarization underlying a burst of spikes or oscillations. The test pulse elicited only the small, short-latency response.

The latencies, overall response patterns, and severe pairedpulse depression of the complex responses in the olfactory and accessory lobes agree closely with previous intracellular recordings from individual interneurons in these lobes. Those recordings demonstrated that all known olfactory and accessory lobe interneuron types show no response to a test pulse at the 300-400 msec interstimulus intervals used here (Wachowiak and Ache, 1994; Wachowiak et al., 1995, 1997). Thus, as in our previous study (Wachowiak and Cohen, 1998), we conclude that the olfactory lobe signal evoked by the test pulse to the antennular nerve selectively reflects action potential activity in the incoming olfactory receptor cell axons.

\section{Presynaptic inhibition revealed by synaptic blockade}

The bottom traces in Figure $1 C$ show that perfusion of the brain with $\mathrm{Ca}^{2+}$-free saline blocked or severely attenuated synaptic transmission, as seen by the elimination of the complex, longlatency component of the accessory lobe signal, which receives only second-order inputs via olfactory lobe interneurons (Wachowiak et al., 1995). The remaining small, short-latency component likely reflects activation of nonolfactory afferents from the antennular nerve passing underneath the accessory lobe. This component has a latency similar to that of the antennular nerve response and was not seen in the bath-stained preparations in which the deep tissue underlying the accessory lobe was unstained. In the olfactory lobe, perfusion with $\mathrm{Ca}^{2+}$-free saline initially resulted in a delayed and prolonged depolarization after the conditioning pulse that eventually disappeared after 5-10 min of continued perfusion (data not shown). As reported previously (Wachowiak and Cohen, 1998), intracellular recordings from olfactory lobe projection neurons confirm that $\mathrm{Ca}^{2+}$-free saline blocks or severely attenuates synaptic transmission from receptor cells to interneurons. The final response pattern in the olfactory lobe (Fig. $1 \mathrm{~B}$, bottom trace), which persisted for as long as $\mathrm{Ca}^{2+}$ free saline was present, consisted of a simple short-duration spike, similar in latency to the evoked antennular nerve signal. In perfusion-stained preparations $(n=8)$, where the optical signal is dominated by activity in interneurons, the conditioning pulse response in $\mathrm{Ca}^{2+}$-free saline was $36 \pm 9 \%$ of its amplitude in normal saline, with a latency to peak $2-3$ msec shorter in $\mathrm{Ca}^{2+}$ free saline. This decrease was smaller in the two bath-stained preparations $(72 \pm 3 \%$ of normal), where the optical signal is dominated by activity in receptor cells and superficially branching interneurons (data not shown). In subsequent analyses, we group the data from both bath- and perfusion-stained preparations.

In contrast, the amplitude of the test response showed a significant increase in the presence of $\mathrm{Ca}^{2+}$-free saline (Fig. $1 \mathrm{~B}$, bottom trace). In 10 preparations, the amplitude of the test response increased to $149 \pm 15 \%$ (mean \pm SEM) of its value in normal saline $(p=0.009$; one-sample $t$ test, hypothesized mean $=100)$, whereas the amplitude of the conditioning response decreased to $38 \pm 6 \%$ of its control value $(p<0.0001)$. These results agree with those of our preliminary study, in which $1 \mathrm{mM} \mathrm{Ca}^{2+}$ was used to reduce synaptic transmission (Wachowiak and Cohen, 1998). The increase in test response amplitude reflects an increase in the action potential signal in the primary olfactory afferents under conditions of synaptic blockade. The simplest explanation of this result is the elimination or reduction of the normal, synaptically 


\section{LOBSTER OLFACTORY LOBE - VOLTAGE DYE}

A.

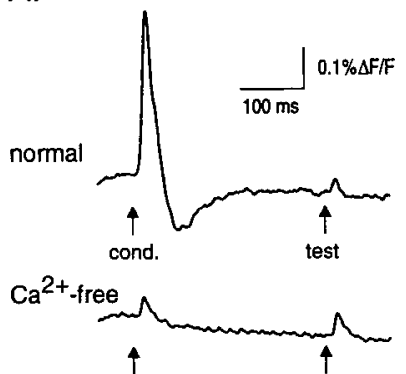

GABA

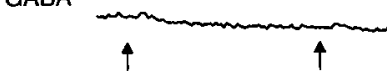

GABA
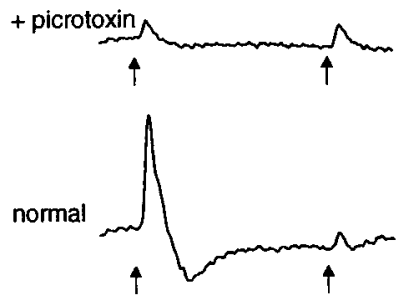

B.

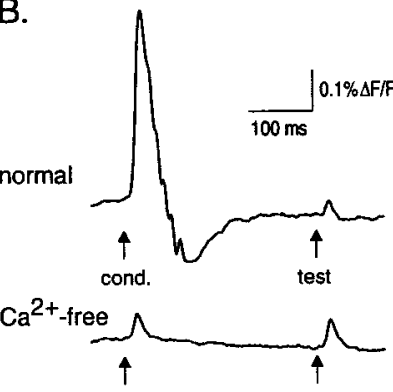

histamine
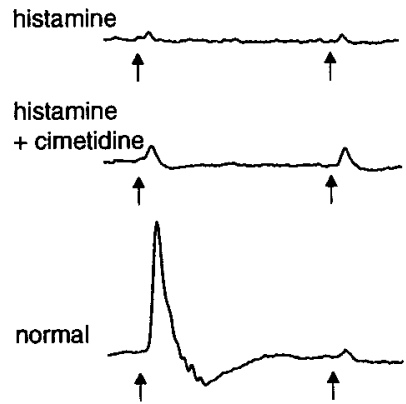

Figure 2. Effect of $\mathrm{Ca}^{2+}$-free saline, GABA, histamine, and antagonists on the olfactory lobe response evoked by paired pulses. $A, \mathrm{Ca}^{2+}$-free saline eliminates postsynaptic components of the conditioning response and increases the amplitude of the test response. GABA $(100 \mu \mathrm{M})$ nearly eliminates both evoked responses, and the effect of GABA is blocked in the presence of $100 \mu \mathrm{M}$ picrotoxin. Finally, the evoked response recovers to its initial pattern after washout in normal saline. $B$, A different preparation than in $A$. Again, $\mathrm{Ca}^{2+}$-free saline eliminates postsynaptic activity and increases the test response amplitude. Histamine $(30 \mu \mathrm{M})$ nearly eliminates the evoked response, and this effect is blocked by $5 \mathrm{~mm}$ cimetidine, followed by recovery in normal saline. In $A$ and $B$, a reduction in absolute response amplitude attributable to dye washout can be seen by comparing the top and bottom traces. The change in test response amplitude at these two time points was used to estimate the rate of dye washout, which was used as a correction factor when normalizing response amplitudes for computing the values shown in Figures 3 and 5. The undershoot in the top and bottom traces is attributable to the digital high-pass RC filter. Digital filtering was performed as described in Figure 1 using lowand high-pass cutoffs of 5.7 and $60 \mathrm{~Hz}$.

mediated suppression of action potential propagation into the terminals that occurs in normal saline. Although the conditioning and test pulse responses had identical waveforms in $\mathrm{Ca}^{2+}$-free saline, we observed that the test response was slightly, but significantly, greater in amplitude than the conditioning response $(12 \pm$ $3 \% ; n=10 ; p=0.001$ ) (Figs. $1 B, 2$ ). This difference was much less than the amount by which the test response increased in $\mathrm{Ca}^{2+}$-free saline. Because of its persistence and uncertain importance, we propose to name this enhancement of the test response the Cohen Effect.

\section{Transmitters mediating presynaptic afferent inhibition in the lobster}

The transmitters GABA and histamine both mediate inhibition in the lobster olfactory lobe via distinct receptors (Wachowiak and Ache, 1997). The histamine receptor is weakly antagonized by cimetidine, whereas the GABA receptor is antagonized by picrotoxin but not bicuculline (Zhainazarov et al., 1997). We tested the ability of the two transmitters to mediate inhibition of olfactory afferents by perfusion-application in the presence of $\mathrm{Ca}^{2+}$ free saline. Both transmitters significantly and reversibly reduced

\section{LOBSTER OLFACTORY LOBE - VOLTAGE DYE}

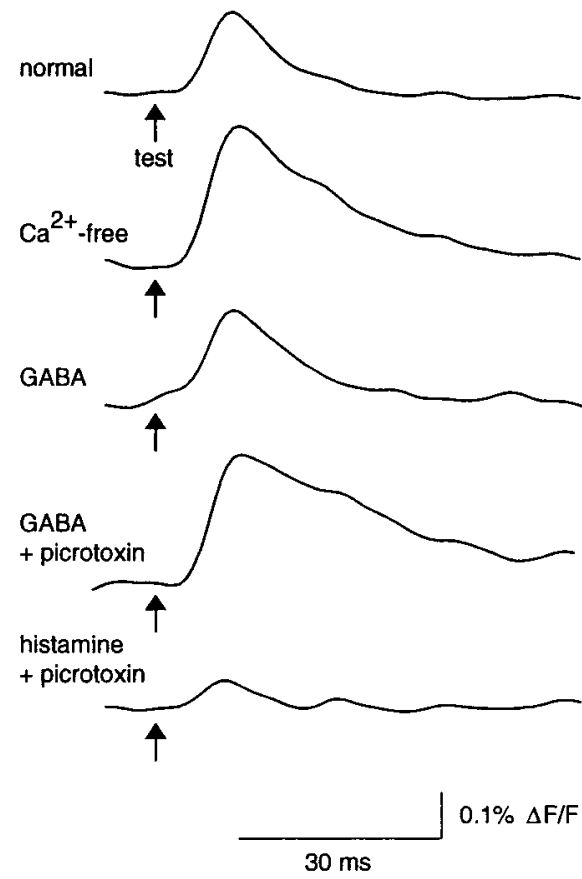

Figure 3. GABA and histamine mediate suppression of primary afferent activation via distinct receptor pathways. Traces shown are from one experiment in which suppression of the afferent signal was caused by GABA $(100 \mu \mathrm{M})$ perfusion, followed by a block of the suppression by picrotoxin $(100 \mu \mathrm{M})$. Histamine $(100 \mu \mathrm{M})$ and picrotoxin were then copresented, resulting in a strong suppression. The afferent signal recovered on washout (data not shown). Digital filter cutoffs were 2.8 and $60 \mathrm{~Hz}$.

the amplitude of the olfactory lobe spike signal in $\mathrm{Ca}^{2+}$-free saline (Fig. 2). The effects of histamine and GABA appeared dose-dependent, with histamine more potent than GABA in reducing the spike amplitude. Histamine $(30 \mu \mathrm{M})$ reduced the evoked response amplitude by $61 \pm 8 \%(n=3)$, whereas the same concentration of GABA did not reduce the response $(0 \pm 1 \%$ reduction; $n=2)$. Likewise, $100 \mu \mathrm{M}$ histamine caused a significantly greater reduction $(82 \pm 7 \%, n=4)$ than did $100 \mu \mathrm{M} \mathrm{GABA}$ $(45 \pm 10 \%, n=5 ; p=0.025)$.

The effects of GABA and histamine were selectively blocked by their respective receptor antagonists (Fig. 2). In two experiments, one of which is shown in Figure 3, the effect of GABA on the olfactory lobe response was antagonized by picrotoxin, after which histamine, still in a picrotoxin background, was applied. In both cases, histamine greatly reduced the response amplitude, indicating that GABA and histamine mediate suppression of receptor cell activity via distinct receptor pathways. As summarized in Figure 4, across all preparations that were tested, picrotoxin $(100 \mu \mathrm{M})$ reduced the effect of $100 \mu \mathrm{M}$ GABA by $96 \pm 2 \%$ ( $n=4 ; p<0.0001)$ but did not change the effect of histamine. Likewise, cimetidine $(5 \mathrm{~mm})$ reduced the effect of $30 \mu \mathrm{M}$ histamine by $59 \pm 6 \%(n=3 ; p<0.001)$ but did not change the effect of GABA. In three experiments, bicuculline methiodide ( 0.1 and 1 $\mathrm{mM}$ ) failed to reduce the suppression mediated by $60 \mu \mathrm{M}$ GABA.

\section{Axonal sensitivity to GABA and histamine-mediated suppression}

We tested the possibility that lobster olfactory receptor axons express GABA and histamine receptors at sites other than their 


\section{LOBSTER}

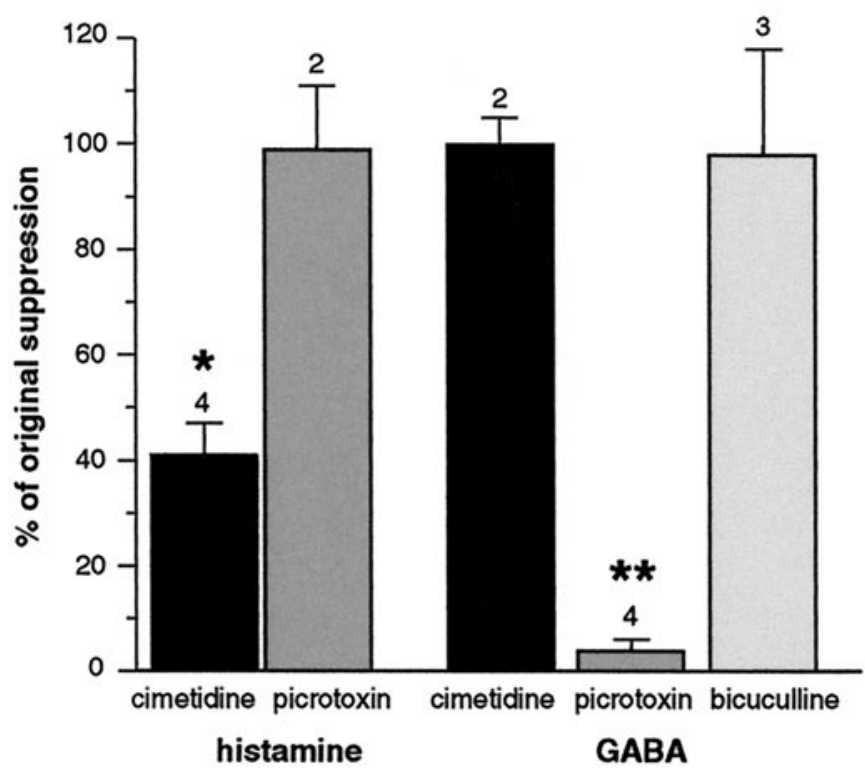

Figure 4. Effect of antagonists on suppression mediated by histamine and GABA in the lobster. The vertical axis represents the percentage of suppression, originally elicited by the agonist, that persists in the presence of the antagonist. Thus, $100 \%$ means that the suppression was unchanged in the presence of antagonist. Suppression caused by histamine $(30 \mu \mathrm{M})$ was reduced by cimetidine $(5 \mathrm{mM})$ but not picrotoxin $(100 \mu \mathrm{M})$, whereas suppression caused by GABA $(100 \mu \mathrm{M})$ was blocked by picrotoxin but not cimetidine or bicuculline. Data from the bicuculline experiments include different concentrations of GABA and bicuculline (100 and $60 \mu \mathrm{M}$ GABA vs $100 \mu \mathrm{M}$ bicuculline, and $60 \mu \mathrm{M}$ GABA vs $1 \mathrm{~mm}$ bicuculline). Error bars indicate standard error; numbers indicate number of experiments. Asterisks indicate significance of difference from agonist alone (100\%); ${ }^{*} p<$ $0.001 ; * *<0.0001$.

terminal branches and their peripheral somata by optically recording compound action potentials in an isolated section of the antennular nerve. The length of nerve was taken just distal to its entrance into the brain, and so contained sections of olfactory receptor axons between 2 and $10 \mathrm{~mm}$ from their terminal regions. We measured the effect of GABA and histamine on the amplitude of the compound action potential. GABA and histamine were each capable of suppressing action potentials in antennular nerve axons: $300 \mu \mathrm{M}$ GABA was tested in four preparations and caused a $49 \pm 11 \%(p=0.013)$ reduction in compound action potential amplitude, whereas $300 \mu \mathrm{M}$ histamine was tested in two preparations and caused reductions of 31 and 58\%. In the two preparations tested, $100 \mu \mathrm{M}$ picrotoxin greatly reduced the effect of GABA (100 and $73 \%$ recovery of amplitude in normal saline).

In addition to containing the small-diameter $(<1-5 \mu \mathrm{m})$ olfactory receptor axons, the antennular nerve also contains a smaller number of large-diameter $(10-50 \mu \mathrm{m})$ afferents originating from other sensory cells on the antennule (Schmidt and Ache, 1992). In two preparations (data not shown), a small peak could be seen in addition to the large, primary peak of the compound action potential. The smaller peak preceded the major peak and, in the one preparation where this was measured, had a lower threshold stimulus intensity. The smaller peak presumably reflects the activation of the larger-diameter fibers, which would have a faster conduction velocity and lower threshold and produce a smaller optical signal because of the relatively small number present in the nerve. GABA was applied to the nerve in both of these preparations, and in both cases the early peak appeared to be unaffected, whereas GABA did reduce the size of the second, larger peak, and this effect was reversed by picrotoxin. This result suggests that GABA receptors are expressed selectively on the olfactory axons and not on the larger-diameter afferents.

\section{Voltage-sensitive dye recordings in turtle olfactory bulb}

We used the same paired-pulse stimulation and $\mathrm{Ca}^{2+}$-free perfusion protocol to record action potential propagation into axon terminals of olfactory receptor neurons in the isolated olfactory bulb of the box turtle $T$. carolina. In normal turtle Ringer's solution, a single conditioning shock to the olfactory nerve elicited a brief, large-amplitude spike that could be observed propagating caudally across the bulb, followed by a smaller, slowly decaying depolarization (Fig. 5A). The initial spike presumably reflects action potentials in incoming receptor cell axons, whereas the slow component reflects the activation of postsynaptic neurons. The slow, postsynaptic component could not be detected in the rostral region and became progressively larger in more caudal regions of the bulb. The test pulse, delivered at the same ISI used in the lobster experiments, elicited an identical initial transient but a much smaller-amplitude and shorter-duration slow component (Fig. 5A).

In six preparations, replacement of the normal Ringer's solution with $\mathrm{Ca}^{2+}$-free/high- $\mathrm{Mg}^{2+}$ Ringer's solution significantly reduced the slow, postsynaptic component but did not affect the initial fast component reflecting receptor axon action potentials (Fig. $5 B$ ). The amplitude of the test pulse-evoked spike in $\mathrm{Ca}^{2+}$ free Ringer's solution was $97 \pm 3 \%(n=6)$ of its control value $(p=0.3)$, whereas the amplitude of the slow component, measured $25 \mathrm{msec}$ after the spike, was $50 \pm 4 \%$ of control $(p<$ $0.0001)$. Thus, action potential propagation in turtle olfactory receptor axons does not show paired-pulse suppression as observed in the lobster.

Superfusion of the bulb with $1 \mathrm{~mm}$ GABA or $1 \mathrm{~mm}$ dopamine in normal Ringer's solution greatly reduced or eliminated the slow component of the evoked response with little or no effect on the fast component (Fig. 6A). In one experiment, the $\mathrm{D}_{2}$ receptor agonist quinpirole $(100 \mu \mathrm{M})$ also reduced the slow component (data not shown). In $\mathrm{Ca}^{2+}$-free ringers (which eliminated postsynaptic signals), GABA, dopamine, and quinpirole did not affect the amplitude or time course of the fast receptor axon component (Fig. 6B). The mean amplitude of the test pulse response in $\mathrm{Ca}^{2+}$-free ringers was $103 \pm 3 \%$ of control values when GABA was applied $(n=4 ; p=0.34)$ and $102 \pm 6 \%$ for dopamine application $(n=3 ; p=0.75)$. Thus, while exogenous GABA and dopamine inhibit postsynaptic events in the turtle olfactory bulb, neither transmitter affects action potentials in the receptor axon terminals.

\section{Calcium dye recordings in turtle olfactory bulb}

To test whether presynaptic inhibition might be mediated by processes subsequent to action potential invasion of the axon terminal, we selectively labeled olfactory afferents by applying a dextran-conjugated calcium indicator to the olfactory epithelium and allowing anterograde transport to the terminals in the olfactory bulb (Friedrich and Korsching, 1997) (see Materials and Methods). Figure $7 A$ shows the optical signal evoked by olfactory nerve shock using the calcium dye (Calcium Crimson, $10 \mathrm{kDa}$ ), superimposed on the optical signal from the same location on the 


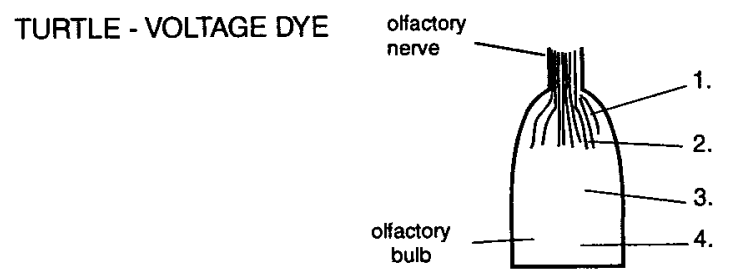

A. normal
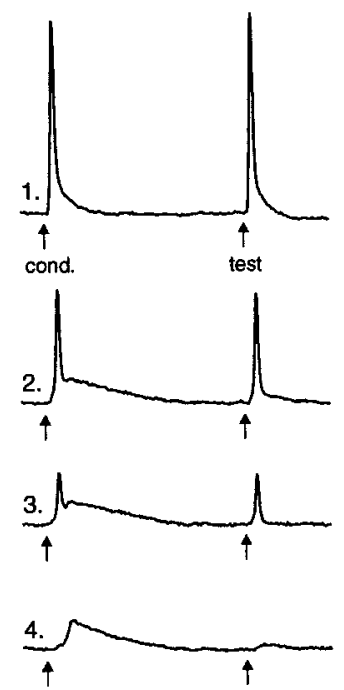

B. $\mathrm{Ca}^{2+}$-free
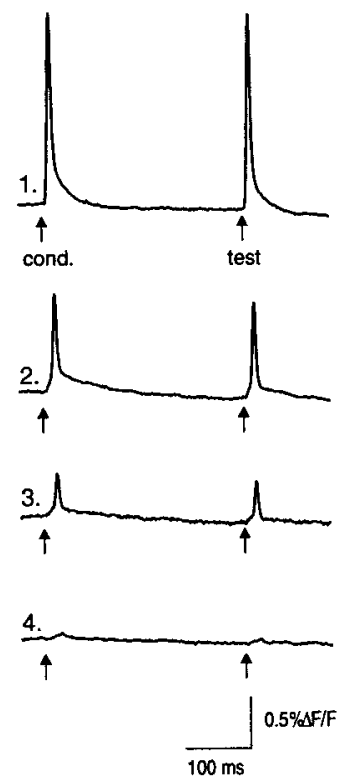

Figure 5. Voltage-sensitive dye signals in in vitro turtle olfactory bulb. The action potential signals are not suppressed by a conditioning pulse and are not changed after bathing in $\mathrm{Ca}^{2+}$-free saline. $A$, Responses to paired-pulse stimulation recorded from four locations, indicated on the drawing of the olfactory bulb at left. Rostrally, the evoked signal is dominated by the compound action potential from olfactory receptor axons (trace 1). In the middle bulb the signal consists of a fast receptor axon component and a slow depolarizing component (traces 2 and 3 ). The slow component of the test pulse response is strongly suppressed. In the caudal bulb, mainly the slow component is seen, and it too shows strong suppression of the test response (trace 4). B, Evoked responses in $\mathrm{Ca}^{2+}$ free Ringer's solution. Same detectors and same preparation as in $A$ are shown. The slow components in the middle and caudal regions are significantly reduced, whereas the compound action potential in the rostral region is unaffected. The peak amplitude of the fast component in traces 2 and 3 is slightly smaller in $\mathrm{Ca}^{2+}$-free Ringer's solution, possibly because of the reduction of the underlying slow component. Digital filter cutoffs are 1.4 and $200 \mathrm{~Hz}$.

olfactory bulb after staining with the voltage-sensitive dye di-4ANEPPS. The calcium signal is slightly delayed, slower in rise time, and much longer lasting. In contrast to other figures, both traces are shown with no digital high-pass filtering. Superfusing the preparation with $\mathrm{Ca}^{2+}$-free Ringer's solution eliminated the evoked calcium signal (data not shown).

With paired-pulse stimulation (300-400 msec ISI), the peak amplitude of the test pulse showed substantial suppression (46 \pm $3 \%$ of conditioning pulse amplitude; $n=12 ; p<0.0001$ ) (Fig. $7 B$, top trace). Because the calcium signal evoked by a single shock decayed very slowly, the apparent suppression could have been caused by saturation of the dye when the test pulse-evoked calcium influx summated with the residual calcium levels evoked by the conditioning pulse (Fig. $7 B$, top trace). We tested this possi-

TURTLE - VOLTAGE DYE

\section{A. normal ringers}
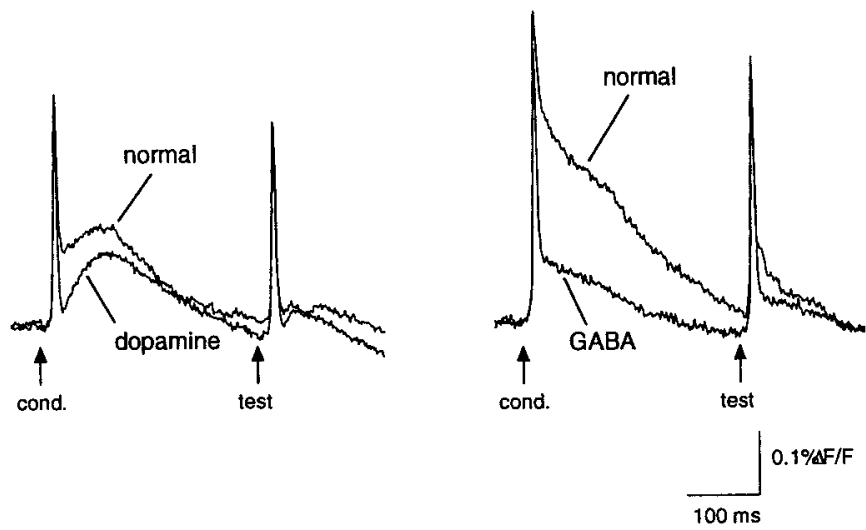

B. $\mathrm{Ca}^{2+}$-free ringers
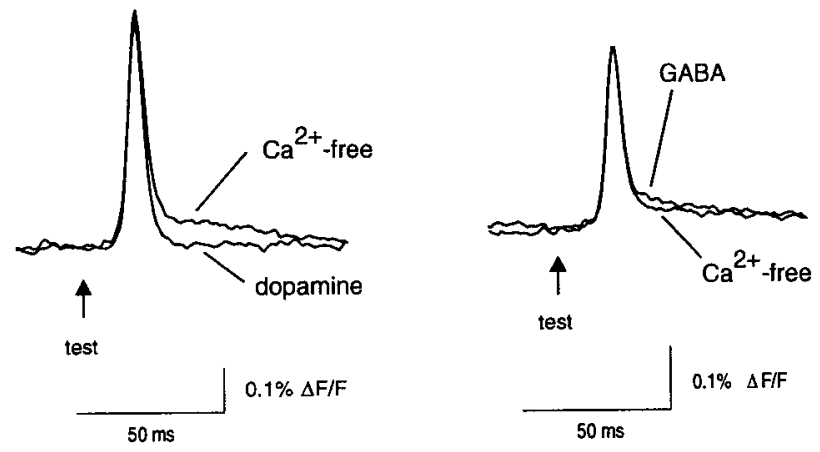

Figure 6. GABA and dopamine suppress postsynaptic activity but do not affect receptor cell action potentials in turtle olfactory bulb. $A$, Effect of GABA and dopamine in normal turtle Ringer's solution. Dopamine (left traces) and GABA (right traces), both $1 \mathrm{~mm}$, significantly reduce the slow, postsynaptic component of the evoked response. The left and right traces were taken from the same preparation but from different detectors. $B$, Effect of GABA and dopamine (1 mM) on the test response in $\mathrm{Ca}^{2+}$-free Ringer's solution. Control and drug traces are superimposed. Dopamine eliminates the remaining slow component of the evoked response but does not affect the compound action potential amplitude. GABA has little effect on the slow component and no effect on action potential amplitude. Same detectors and preparation as in $A$ are shown. Digital filter cutoffs are $1.4-200 \mathrm{~Hz}$.

bility in each preparation by delivering a series of three shocks at $50 \mathrm{msec}$ intervals. As shown in Figure $7 B$ (bottom trace), each shock caused progressively smaller increases in calcium, but because of the slow decay, the total calcium signal summated to levels above that evoked by the conditioning pulse, indicating that the suppression of the test response was not a result of dye saturation. Because there was no evidence for dye saturation in the evoked signals, in Figures 8 and 9 the data were digitally high-pass-filtered using a numerical $\mathrm{RC}$ filter with a time constant of $1.4 \mathrm{~Hz}$.

The same protocol used in the voltage-sensitive dye recordings was used to test for transmitter-mediated suppression of calcium influx into turtle olfactory receptor cell axon terminals, except that all experiments were performed in normal turtle Ringer's solution. A mixture of the NMDA receptor antagonist AP5 (100 $\mu \mathrm{M})$ and the non-NMDA receptor antagonist DNQX (10 uM) was 


\section{TURTLE}

\section{A. Comparison of calcium and voltage signals}

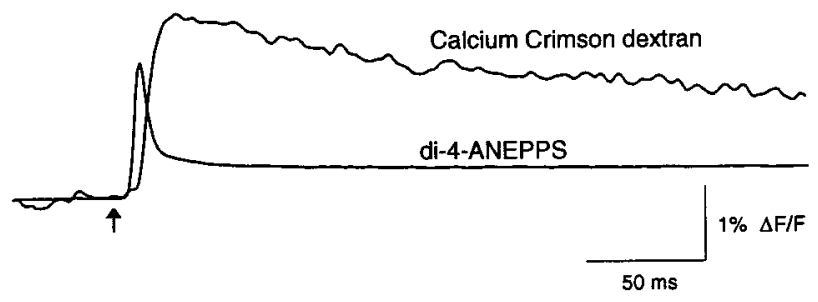

B. Calcium Green-1 dextran

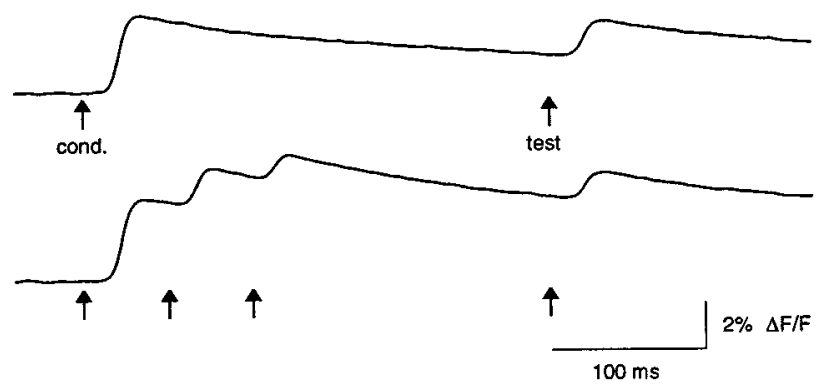

Figure 7. Optical signals recorded with dextran-conjugated calcium indicators in turtle olfactory afferent terminals. $A$, The calcium- and voltage-sensitive dye signals evoked by olfactory nerve shock. The $\mathrm{Cal}$ cium Crimson dextran signal was recorded first, then the olfactory bulb was stained with di-4-ANEPPS and the voltage-sensitive dye signal was recorded using the same wavelength filters, stimulus intensity, and detectors. Traces were digitally low-pass-filtered at $200 \mathrm{~Hz}$ (no high-pass filtering). B, Calcium signal recorded with Calcium Green-1 dextran, demonstrating paired-pulse suppression of evoked calcium influx (top trace). Bottom trace shows repetitive stimulation of the olfactory nerve (arrows) causing summation of calcium levels in the nerve terminal, indicating that the paired-pulse suppression did not result from saturation of the calcium dye. In these and all subsequent traces, upward indicates an increase in fluorescence intensity (and $\mathrm{Ca}^{2+}$ levels). Traces were digitally low-pass-filtered at $30 \mathrm{~Hz}$.

used to reduce glutamatergic transmission from receptor cells to olfactory bulb neurons (Berkowicz et al., 1994). In separate preparations stained with voltage-sensitive dye, AP5/DNQX caused a large, although not complete, suppression of the slow, postsynaptic component of the evoked response and a partial suppression of the fast component ( $n=2$; data not shown). As shown in the example of Figure $8 A$, in preparations stained with calcium dye, AP5/DNQX caused a significant and reversible increase in calcium influx after the test pulse $(134 \pm 7 \% ; n=4$; $p=0.01)$ without affecting conditioning pulse-evoked influx (98 $\pm 2 \% ; n=4 ; p=0.2)$. Thus, AP5/DNQX significantly reduced paired-pulse suppression, indicating that calcium influx into olfactory receptor cell axon terminals is suppressed by evoked postsynaptic activity in the olfactory bulb.

In contrast to the voltage-sensitive dye results in the turtle (Fig. $6)$, GABA ( $1 \mathrm{~mm} ; n=5)$ significantly and reversibly reduced the amplitude of both the conditioning and test pulses to $57 \pm 8 \%$ $(p=0.005)$ and $66 \pm 6 \%(p=0.006)$, respectively, of their initial values (Fig. $8 B$ ). The $\mathrm{D}_{2}$ agonist quinpirole $(100 \mu \mathrm{M} ; n=5)$ also affected calcium influx, reducing the conditioning and test responses to $77 \pm 4 \%(p=0.04)$ and $86 \pm 5 \%(p=0.06)$ of their

\section{TURTLE - CALCIUM DYE}

A.

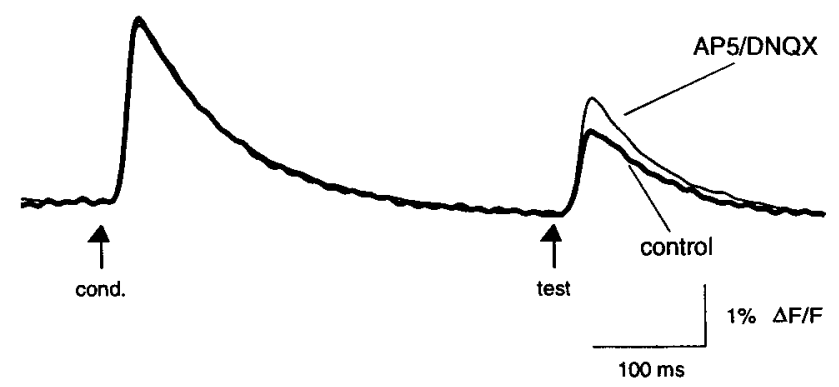

B.

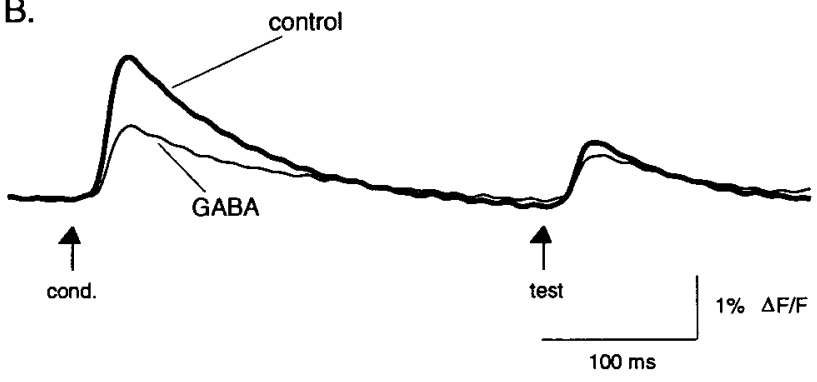

C.

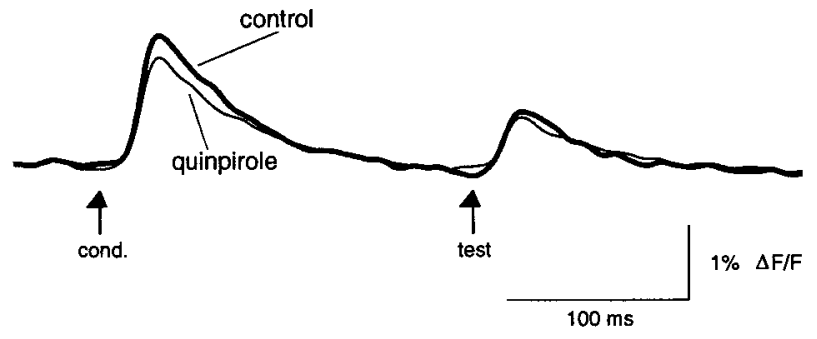

Figure 8. Effect of the glutamate receptor antagonists AP5 and DNQX, the transmitter GABA, and the dopamine $\mathrm{D}_{2}$ agonist quinpirole on evoked calcium influx. $A$, Reducing glutamatergic transmission from receptor cells to olfactory bulb interneurons reduces paired-pulse suppression by increasing the test response. Superimposed traces are in normal turtle Ringer's solution and a mixture of AP5 $(100 \mu \mathrm{M})$ and DNQX (10 $\mu \mathrm{M})$. B, Superimposed traces in normal turtle Ringer's solution and $1 \mathrm{mM}$ GABA. $C$, Superimposed traces in normal Ringer's solution and $100 \mu \mathrm{M}$ quinpirole. $A-C$ are from different preparations. In $B$ and $C$, the conditioning response shows the greatest amount of suppression. Recovery is not shown. Digital filter cutoffs are 1.4 and $30 \mathrm{~Hz}$.

initial amplitudes (Fig. 8C). The effects of quinpirole were long lasting, with responses showing only partial recovery as much as 30 min after returning to normal saline.

Baclofen $(50 \mu \mathrm{M} ; n=3)$, a $\mathrm{GABA}_{\mathrm{B}}$ agonist, strongly inhibited evoked calcium influx (Fig. $9 A$ ), reducing the conditioning response amplitude to $27 \pm 2 \%(p=0.001)$ of its original amplitude, and a reduction to $62 \pm 9 \%(p=0.04)$ for the test response. Both baclofen and quinpirole had significantly greater effects on the conditioning versus the test responses (baclofen, $p=0.01$; quinpirole, $p=0.02$; unpaired $t$ test) (Figs. $8 C, 9 A$ ). Likewise, 10 $\mu \mathrm{M}$ baclofen, tested in one experiment, reduced the conditioning response to $59 \%$ of the control value and did not affect the test response. One result of this preferential effect of baclofen was to reduce or nearly eliminate paired-pulse suppression of calcium influx. Interestingly, in all baclofen experiments, the strength of 


\section{TURTLE - CALCIUM DYE}

A.
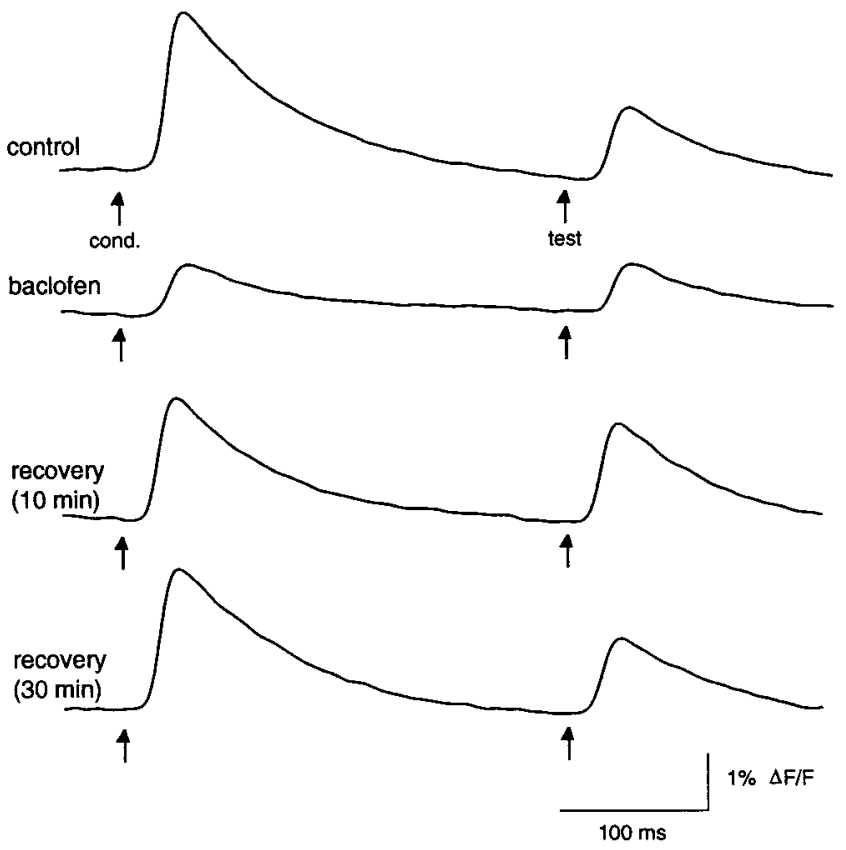

B.

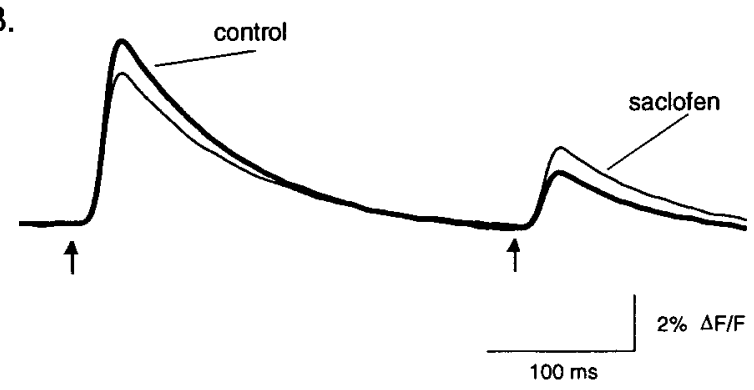

Figure 9. Effect of the $\mathrm{GABA}_{\mathrm{B}}$ agonist baclofen and the antagonist saclofen on evoked calcium influx. $A$, Baclofen $(50 \mu \mathrm{M})$ preferentially suppresses the conditioning response so that both the conditioning and test pulses are of similar amplitude (top two traces). Recovery of the paired-pulse suppression has a longer time course than recovery of the stimulus-evoked calcium levels, so that after $10 \mathrm{~min}$ of baclofen washout the test pulse is actually larger in amplitude than before baclofen application (third trace). After prolonged washout, paired-pulse suppression recovers fully (bottom trace). $B$, Saclofen $(200 \mu \mathrm{M})$ reduces paired-pulse suppression of calcium influx, causing an increase in the test response amplitude as well as a smaller decrease in the conditioning response. Recovery is not shown. Digital filter cutoffs are 1.4 and $30 \mathrm{~Hz}$.

paired-pulse suppression remained attenuated for up to $20 \mathrm{~min}$ after washout of baclofen, whereas the effect on the absolute response amplitude recovered after 5-10 min of washout (Fig. 9A).

A likely explanation for the preferential effect of baclofen (and quinpirole) on the conditioning response is that the paired-pulse suppression already reflects $\mathrm{GABA}_{\mathrm{B}^{-}}$(and $\mathrm{D}_{2^{-}}$)mediated inhibition of $\mathrm{Ca}^{2+}$ influx evoked by the conditioning pulse. We therefore measured the effect of the $\mathrm{GABA}_{\mathrm{B}}$ antagonist saclofen on the test response amplitude. Saclofen $(200 \mu \mathrm{M} ; n=5)$ significantly increased the test response to $120 \pm 6 \%(p=0.03)$ of its control value (Fig. $9 B$ ), supporting the idea that paired-pulse suppression is at least partially mediated by $\mathrm{GABA}_{\mathrm{B}}$ receptors activated by
GABA release from olfactory bulb interneurons. At the same time, saclofen caused a slight decrease in the amplitude of the conditioning response, to $88 \pm 3 \%(p=0.01)$ of its control value.

\section{DISCUSSION}

The results from the experiments on the lobster extend the findings of our preliminary study (Wachowiak and Cohen, 1998) showing that antennular nerve shock causes a long-lasting suppression of action potential propagation in olfactory receptor axon terminals. Because no known olfactory lobe interneurons show any response to a test shock at the ISIs used in this study [>200 neurons tested in earlier studies (Wachowiak et al., 1995, 1997)], the test pulse-evoked voltage-sensitive dye signal is a selective measure of receptor cell activation. In the present experiments, presynaptic inhibition was revealed experimentally as an increase in amplitude of the test pulse response after synaptic blockade with zero $\mathrm{Ca}^{2+} /$ high- $\mathrm{Mg}^{2+}$ saline. In contrast to our preliminary study, which used low $(1 \mathrm{~mm}) \mathrm{Ca}^{2+}$ to reduce (but not eliminate) synaptic transmission, in the present experiments we saw no evidence of postsynaptic activity in the olfactory or accessory lobes in the presence of zero $\mathrm{Ca}^{2+}$ saline. Nonetheless, the increase in test response amplitude was similar in the two studies: $57 \pm 16 \%$ in the initial study versus $49 \pm 15 \%$ in the present study.

Our results in the lobster do not discriminate between whether presynaptic inhibition is mediated by reduced action potential amplitude or by conduction failure in the terminal region. However, both phenomena are well documented in sensory afferent terminals of crustaceans and insects (Boyan, 1988; Burrows and Laurent, 1993; Clarac and Cattaert, 1996). Because the terminal branching regions of sensory afferents in the arthropod CNS appear to be largely passive, shunting conductances such as those mediated by ionotropic GABA and histamine receptors can have a large effect on action potential amplitude at the axon terminal and, subsequently, on transmitter release (Clarac and Cattaert, 1996).

\section{Dual regulation of olfactory input in the lobster}

The voltage-sensitive dye signal in lobster olfactory afferent terminals was suppressed by exogenous GABA or histamine, two known inhibitory transmitters in the lobster olfactory lobe (Wachowiak and Ache, 1997). The suppression caused by each transmitter was selectively blocked by known antagonists for GABA and histamine receptors, suggesting that GABA and histaminergic interneurons in the olfactory lobe constitute dual, functionally independent inhibitory pathways mediating presynaptic inhibition. Interestingly, GABA and histamine also mediate presynaptic inhibition of sensory afferents in the crayfish thoracic ganglion (el Manira and Clarac, 1994), as well as postsynaptic inhibitory events in the lobster olfactory lobe (Wachowiak and Ache, 1997).

Differences in the morphology of GABA and histaminergic interneurons suggest that GABA- and histamine-mediated presynaptic afferent inhibition may serve distinct functional roles in olfactory processing. Type II olfactory lobe interneurons, which appear to be GABAergic, have extensive lateral branches innervating many adjacent glomeruli (Wachowiak et al., 1997). Thus, GABAergic interneurons appear well suited to mediate widespread lateral inhibition of olfactory afferent input. This inhibition could serve to sharpen the receptive fields of neurons innervating a particular glomerulus. By contrast, the individual neurites of type I interneurons, which appear to be histaminergic, remain confined to a single glomerulus (Wachowiak et al., 1997). 
This branching pattern leads us to speculate that histaminemediated presynaptic inhibition may regulate input to a specific postsynaptic target and refine intraglomerular processing. In addition, the histaminergic type I interneurons respond to olfactory nerve shock with a spike burst and a prolonged depolarization lasting from 1 to $10 \mathrm{sec}$ (Wachowiak et al., 1997), suggesting that presynaptic inhibition mediated by these neurons could underlie the prolonged paired-pulse suppression of olfactory lobe projection neurons (Wachowiak and Ache, 1994).

\section{Distribution of GABA and histamine receptors on lobster olfactory afferents}

Receptors for GABA and histamine are not only located at the nerve terminal; they are also expressed on the somata of olfactory receptor neurons, where they activate inhibitory conductances (Bayer et al., 1989; Doolin et al., 1998). The absence of endogenous histamine in the periphery (B. W. Ache, personal communication) led to the hypothesis that these receptors are also expressed on the receptor cell axon terminal where they mediate presynaptic inhibition, a hypothesis confirmed by our results. In addition, our finding of suppression of the compound action potential in isolated antennular nerve implies that olfactory receptor neurons express GABA and histamine receptors on regions of axon that are up to $10 \mathrm{~mm}$ distant from their terminal branches. Interestingly, this result is similar to studies in mammals showing that $\mathrm{GABA}_{\mathrm{A}}$ receptors suppress compound action potentials in axons of primary sensory afferents (Brown and Marsh, 1978; Morris et al., 1983). High concentrations of GABA and histamine were required to cause suppression in the nerve relative to that seen in the olfactory lobe (300 $\mu \mathrm{M}$ vs $10-30 \mu \mathrm{M})$, and GABA and histamine seemed roughly equally effective in the nerve, whereas histamine was more potent than GABA at causing suppression in the olfactory lobe. Although these differences could reflect lower receptor density in the nerve, they could also be explained by differences in access of agonists to receptors in the two preparations (bath application in the nerve vs perfusion in the brain). The functional relevance of this ectopic expression of transmitter receptors on the cell body and axon remains unknown.

\section{Dual regulation of olfactory input in the turtle}

The paired-pulse suppression of calcium influx in the turtle experiments, and the reduction of this suppression by glutamate receptor antagonists that inhibit synaptic transmission from receptor cells to olfactory bulb interneurons, indicates that olfactory input activates a feedback inhibitory pathway that suppresses subsequent calcium influx into receptor cell terminals, presumably reducing transmission at the primary olfactory synapse. Our experiments also show that presynaptic afferent inhibition occurs without affecting action potentials in the axon terminal. Baclofen and quinpirole, selective agonists for $\mathrm{GABA}_{\mathrm{B}}$ and $\mathrm{D}_{2}$ receptors, respectively, suppressed shock-evoked calcium influx. In other regions of the CNS, including the hippocampus, cerebellum, and striatum, presynaptic $\mathrm{GABA}_{\mathrm{B}}$ and $\mathrm{D}_{2}$ receptors inhibit transmitter release by coupling to G-proteins that directly inhibit voltagesensitive $\mathrm{Ca}^{2+}$ channels (Hsu et al., 1995; for review, see Wu and Saggau, 1997; Miller, 1998). A similar mechanism may underlie GABA- and dopamine-mediated presynaptic inhibition of turtle olfactory afferents.

The reduction of paired-pulse suppression of calcium influx by saclofen and during recovery from baclofen application suggests that this suppression is at least partly mediated by stimulus-
Table 1. Mechanisms mediating presynaptic inhibition of olfactory afferents in lobster and turtle

\begin{tabular}{lll} 
& $\begin{array}{l}\text { Action potential } \\
\text { suppression }\end{array}$ & $\begin{array}{l}\text { Reduced calcium } \\
\text { influx }\end{array}$ \\
\hline $\begin{array}{l}\text { Lobster } \\
\text { Turtle }\end{array}$ & Yes & Not tested \\
& No & Yes \\
\hline
\end{tabular}

evoked release of endogenous GABA, presumably from juxtaglomerular neurons excited by the conditioning pulse. This finding agrees with a recent study showing that $\mathrm{GABA}_{\mathrm{B}}$ antagonists reduce paired-pulse suppression of postsynaptic activity in the rat (Keller et al., 1998). Both GABA and dopamine are found in neurons branching heavily within glomeruli of turtles as well as mammals (Halasz et al., 1982; McLean and Shipley, 1992), and $\mathrm{GABA}_{\mathrm{B}}$ and $\mathrm{D}_{2}$ receptors are present in the glomerular and olfactory nerve layers (Bouthenet et al., 1987; Bowery et al., 1987; Nickell et al., 1991). However, EM studies of the synaptic organization of the mammalian olfactory glomerulus have failed to find classical output synapses from juxtaglomerular interneurons onto receptor cell axon terminals (Pinching and Powell, 1971; White, 1972). Whether classical synapses onto afferent terminals are in fact present in the turtle or whether inhibitory transmitters are released at nonsynaptic sites to affect distant targets, as has been shown for dopamine in several systems (for review, see Maley et al., 1990), are questions for further study. A more complete understanding of the mechanisms underlying presynaptic inhibition of turtle olfactory afferents is clearly necessary; however, our results suggest that this phenomenon plays a significant role in the paired-pulse suppression that is characteristic of olfactory bulb neurons and may also be important in modulating or directly shaping the responses of olfactory bulb neurons to odors. Our results show that two different transmitter substances mediate presynaptic inhibition of olfactory afferents. However, because no other transmitter substances were tested, possible contributions from other transmitters are not ruled out.

\section{Phylogenetic and functional considerations}

The organization of olfactory pathways in vertebrates and invertebrates shares a number of common features that suggest a common functional strategy for processing olfactory input that is shared across phylogenetically distant groups (Boeckh et al., 1990; Ache, 1991; Hildebrand and Shepherd 1997). The present study suggests that presynaptic regulation of transmission from olfactory receptor cells to interneurons may be another feature of this common functional strategy, because in both lobster and turtle, GABAergic and aminergic transmitter pathways appear to act as dual mediators of presynaptic inhibition of olfactory afferents. In addition, physiological evidence supports the existence of presynaptic inhibition in mammals (see above), and in insects, ultrastructural studies show that GABAergic interneurons synapse onto receptor cell terminals (Distler and Boeckh, 1997). Nonetheless, phylogenetic differences are apparent in the cellular mechanisms mediating presynaptic inhibition, because we found no evidence for suppression of action potentials in olfactory receptor terminals in the turtle and pronounced suppression in the lobster (Table 1). We were not able to test whether, in the lobster, transmitters also directly inhibit calcium influx into the terminal as they do in the turtle.

Although our results suggest that presynaptic inhibition plays a significant role in the paired-pulse suppression seen in both turtle 
and lobster, its role in odor processing remains unclear. Presynaptic inhibition mediated by inhibitory interneurons innervating several adjacent glomeruli could directly shape and refine spatial patterns of input across glomeruli. This "pre-glomerular" level of processing would be in addition to glomerular and subglomerular processing steps already characterized in the vertebrate olfactory bulb (for review, see Nickell and Shipley, 1992). Alternatively, presynaptic inhibition could have a modulatory role, regulating sensitivity to olfactory input by controlling the effectiveness of transmission from primary afferents to second-order neurons. Additional experiments are needed to distinguish between this and other possible roles in olfactory coding. Nonetheless, it is interesting to speculate that presynaptic inhibition of olfactory input to the CNS has evolved independently in vertebrates and invertebrates in response to common functional demands in processing odor information.

\section{REFERENCES}

Ache B (1991) Phylogeny of taste and smell. In: Smell and taste in health and disease (Getchell T, Doty R, Bartoshuk L, Snow J, eds), pp 3-18. New York: Raven.

Bayer TA, McClintock TS, Grunert U, Ache BW (1989) Histamineinduced modulation of olfactory receptor neurones in two species of lobster, Panulirus argus and Homarus americanus. J Exp Biol 145:133-146.

Berkowicz DA, Trombley PQ, Shepherd GM (1994) Evidence for glutamate as the olfactory receptor cell neurotransmitter. J Neurophysiol $71: 2557-2561$.

Blagburn JM, Sattelle DB (1987) Presynaptic depolarization mediates presynaptic inhibition at a synapse between an identified mechanosensory neurone and giant interneurone 3 in the first instar cockroach, Periplaneta americana. J Exp Biol 127:135-157.

Boeckh J, Distler P, Ernst KD, Hösl M, Malvin D (1990) Olfactory bulb and antennal lobe. In: Chemosensory information processing (Schild D, ed), pp 201-227. Berlin: Springer.

Bouthenet M, Martres M, Sales N, Schwartz J (1987) A detailed mapping of dopamine D2 receptors in rat central nervous system by autoradiography with [125I]iodosulpride. Neuroscience 20:117-155.

Bowery NG, Hudson AL, Price GW (1987) GABA And $_{\text {GABA }}$ receptor site distribution in the rat central nervous system. Neuroscience 20:365-383.

Boyan GS (1988) Presynaptic inhibition of identified wind-sensitive afferents in the cercal system of the locust. J Neurosci 8:2748-2757.

Brown DA, Marsh S (1978) Axonal GABA-receptors in mammalian peripheral nerve trunks. Brain Res 156:187-191.

Burrows M, Laurent G (1993) Synaptic potentials in the central terminals of locust proprioceptive afferents generated by other afferents form the same sense organ. J Neurosci 13:808-819.

Clarac F, Cattaert D (1996) Invertebrate presynaptic inhibition and motor control. Exp Brain Res 112:163-180.

Distler PG, Boeckh J (1997) Synaptic connections between identified neuron types in the antennal lobe glomeruli of the cockroach, Periplaneta americana: I. Uniglomerular projection neurons. J Comp Neurol 378:307-319.

Doolin RE, Hoegg R, Zhainazarov AB, Ache BW (1998) A GABAinduced chloride current in the soma of lobster olfactory receptor neurons. Chem Senses 23:622.

el Manira A, Clarac F (1994) Presynaptic inhibition is mediated by histamine and GABA in the crustacean escape reaction. J Neurophysiol 71:1088-1095.

Friedrich R, Korsching S (1997) Combinatorial and chemotopic odorant coding in the zebrafish olfactory bulb visualized by optical imaging. Neuron 18:737-752.

Grinvald A, Lieke EE, Frostig RD, Hildesheim R (1994) Cortical pointspread function and long-range lateral interactions revealed by realtime optical imaging of Macaque monkey primary visual cortex. J Neurosci 18:9977-9988.

Halasz N, Nowycky M, Hokfelt T, Shepherd GM, Markey K, Goldstein M (1982) Dopaminergic periglomerular cells in the turtle olfactory bulb. Brain Res Bull 9:383-389.

Hildebrand JG, Shepherd GM (1997) Mechanisms of olfactory discrim- ination: converging evidence for common principles across phyla. Annu Rev Neurosci 20:595-631.

Hsu K, Huang C, Yang C, Gean P (1995) Presynaptic synaptic D2 dopaminergic receptors mediate inhibition of excitatory synaptic transmission in rat neostriatum. Brain Res 690:264-268.

Keller A, Yagodin S, Aroniadou-Anderjaska V, Zimmer L, Ennis M, Sheppard N, Shipley M (1998) Functional organization of rat olfactory bulb glomeruli revealed by optical imaging. J Neurosci 18:2602-2612.

Kleinfeld D, Delaney K (1996) Distributed representation of vibrissa movement in the upper layers of somatosensory cortex revealed with voltage-sensitive dyes. J Comp Neurol 375:89-109.

Maley B, Engle M, Humphreys S, Vascik D, Howes K, Newton B, Elde R (1990) Monoamine synaptic structure and localization in the central nervous system. J Electron Microsc Tech 15:20-33.

McLean J, Shipley M (1992) Neuroanatomical substrates of olfaction. In: Science of olfaction (Serby M, Chobor K, eds), pp 126-171. New York: Springer.

Miller R (1998) Presynaptic receptors. Annu Rev Pharmacol Toxicol 38:201-227.

Mori K, Nowycky MC, Shepherd GM (1984) Synaptic excitatory and inhibitory interactions at distal dendrites on mitral cells in the isolated turtle olfactory bulb. J Neurosci 4:2291-2296.

Morris ME, DoCostanzo GA, Fox S, Werman R (1983) Depolarizing action of GABA (gamma-aminobutyric acid) on myelinated fibers of peripheral nerves. Brain Res 278:117-126.

Nickell WT, Norman AB, Wyatt LM, Shipley MT (1991) Olfactory bulb DA receptors may be located on terminals of the olfactory nerve. NeuroReport 2:9-12.

Nickell WT, Shipley M (1992) Neurophysiology of the olfactory bulb. In: Science of olfaction (Serby M, Chobor K, eds), pp 172-212. New York: Springer.

Nickell WT, Behbehani MM, Shipley MT (1994) Evidence for GABA ${ }^{-}$ mediated inhibition of transmission from the olfactory nerve to mitral cells in the rat olfactory bulb. Brain Res Bull 35:119-123.

Orbach HS, Cohen LB (1983) Optical monitoring of activity from many areas of the in vitro and in vivo salamander olfactory bulb: a new method for studying functional organization in the vertebrate central nervous system. J Neurosci 3:2251-2262.

Pinching AJ, Powell TPS (1971) The neuropil of the periglomerular region of the olfactory bulb. J Cell Sci 9:379-409.

Potapov A (1985) Baclofen inhibition of synaptic transmission in glomeruli of the olfactory bulb of the frog. Neirofiziologiia 17:834-837.

Rudomin P (1990) Presynaptic inhibition of muscle spindle and tendon organ afferents in the mammalian spinal cord. Trends Neurosci $1: 164-166$.

Schmidt M, Ache BW (1992) Antennular projections to the midbrain of the spiny lobster. II. Sensory innervation of the olfactory lobe. J Comp Neurol 318:291-303.

Wachowiak M, Ache B (1994) Morphology and physiology of multiglomerular olfactory projection neurons in the spiny lobster. J Comp Physiol [A] 175:35-48.

Wachowiak M, Ache BW (1997) Dual inhibitory pathways mediated by GABA- and histaminergic interneurons in the lobster olfactory lobe. J Comp Physiol [A] 180:357-372.

Wachowiak M, Cohen LB (1998) Presynaptic afferent inhibition of lobster olfactory receptor cells: reduced action potential propagation into axon terminals. J Neurophysiol 80:1011-1015.

Wachowiak M, Diebel CE, Ache BW (1995) Functional organization of olfactory processing in the accessory lobe of the spiny lobster. J Comp Physiol [A] 178:211-226.

Wachowiak M, Diebel C, Ache B (1997) Local interneurons define functionally distinct regions within lobster olfactory glomeruli. J Exp Biol 200:989-1001.

Watson AHD (1992) Presynaptic modulation of sensory afferents in the invertebrate and vertebrate nervous system. Comp Biochem Physiol A Physiol 103:227-239.

White EL (1972) Synaptic organization in the olfactory glomerulus of the mouse. Brain Res 37:69-80.

Wu LG, Saggau P (1997) Presynaptic inhibition of elicited neurotransmitter release. Trends Neurosci 20:204-212.

Zhainazarov AB, Wachowiak M, Boettcher A, Elenes S, Ache BW (1997) Ionotropic GABA receptor from lobster olfactory projection neurons. J Neurophysiol 77:2235-2251. 